University of Nebraska - Lincoln

DigitalCommons@University of Nebraska - Lincoln

Faculty Publications: Department of

Entomology

Entomology, Department of

2019

Spatial repellency, antifeedant activity and toxicity of three

medium chain fatty acids and their methyl esters of coconut fatty

acid against stable flies

\author{
Gwang H. Roh \\ Agroecosystem Management Research Unit, Agricultural Research Service \\ Xiaaojie Zhou \\ Center for Disease Control and Prevention, Beijing \\ Yansu Wang \\ China Jiliang University, Hangzhou \\ Steven C. Cermak \\ National Center for Agricultural Utilization Research, Peoria \\ James A. Kenar \\ National Center for Agricultural Utilization Research, Peoria
}

See next page for additional authors

Follow this and additional works at: https://digitalcommons.unl.edu/entomologyfacpub

Part of the Entomology Commons

Roh, Gwang H.; Zhou, Xiaaojie; Wang, Yansu; Cermak, Steven C.; Kenar, James A.; Lehmann, Alexander; Han, Baoyu; Taylor, David B.; Zeng, Xiaopeng; Park, Chung Gyoo; Brewer, Gary J.; and Zhu, J.J., "Spatial repellency, antifeedant activity and toxicity of three medium chain fatty acids and their methyl esters of coconut fatty acid against stable flies" (2019). Faculty Publications: Department of Entomology. 860. https://digitalcommons.unl.edu/entomologyfacpub/860

This Article is brought to you for free and open access by the Entomology, Department of at DigitalCommons@University of Nebraska - Lincoln. It has been accepted for inclusion in Faculty Publications: Department of Entomology by an authorized administrator of DigitalCommons@University of Nebraska - Lincoln. 


\section{Authors}

Gwang H. Roh, Xiaaojie Zhou, Yansu Wang, Steven C. Cermak, James A. Kenar, Alexander Lehmann,

Baoyu Han, David B. Taylor, Xiaopeng Zeng, Chung Gyoo Park, Gary J. Brewer, and J.J. Zhu 


\title{
Spatial repellency, antifeedant activity and toxicity of three medium chain fatty acids and their methyl esters of coconut fatty acid against stable flies
}

\author{
Gwang H Roh, ${ }^{\text {a }}$ Xiaaojie Zhou, ${ }^{\text {b }}$ Yansu Wang, ${ }^{c}$ Steven C Cermak, ${ }^{\text {d }}$ \\ James A Kenar, ${ }^{d}$ Alexander Lehmann, ${ }^{e}$ Baoyu Han, ${ }^{c}$ David B Taylor, ${ }^{a}$ \\ Xiaopeng Zeng, ${ }^{\text {d }}$ Chung Gyoo Park, ${ }^{\text {f }}$ Gary J Brewer ${ }^{\mathrm{e}}$ and Junwei J Zhu ${ }^{\mathrm{a}^{*}}$
}

\begin{abstract}
BACKGROUND: Stable flies are one of the most detrimental arthropod pests to livestock. With changing climates and agronomic practices, they expand their roles as pests and disease vectors as well. Their painful bites reduce livestock productivity, annoy companion animals, and interfere with human recreational activities. Current management technologies are unable to effectively control stable flies. The present study reports new results concerning the contact, spatial repellency, and toxicity of a bio-based product, coconut fatty acid and their methyl ester derivatives of free fatty acids of $C_{8: 0}, C_{10: 0}$ and $C_{12: 0}$ to stable flies.

RESULTS: Three medium chain fatty acid methyl esters $\left(C_{8: 0}, C_{10: 0}\right.$ and $\left.C_{12: 0}\right)$ showed strong antifeedant activity against stable flies and their strengths were dose-dependent. Only the $C_{8: 0}$ acid, $C_{8: 0}$ - and $C_{10: 0}$ methyl esters elicited significant antennal responses. Laboratory single cage olfactometer bioassays revealed that coconut fatty acid and $\mathrm{C}_{8: 0}$ methyl ester displayed active spatial repellency. All three methyl esters showed strong toxicity against stable flies.
\end{abstract}

CONCLUSION: Antifeedant activity is the main method through which coconut fatty acid deters stable fly blood-feeding. The $C_{8: 0}, C_{10: 0}$ and $C_{12: 0}$ methyl esters act not only as strong antifeedants, but also possess strong toxicity against stable fly adults. Limited spatial repellency was observed from coconut fatty acid and $\mathrm{C}_{8: 0}$ methyl ester.

(C) 2019 Society of Chemical Industry

Keywords: Stomoxys calcitrans; coconut fatty acids; methyl esters; spatial repellent; antifeedant activity

\section{INTRODUCTION}

The stable fly, Stomoxys calcitrans (L.), is considered one of the most serious biting fly pests of bovids and equines in livestock feedlot, barns and pasture settings. ${ }^{1}$ In the last decade, outbreaks of stable flies resulting from flies developing in decomposing crop residues have been reported worldwide, with particularly large outbreaks reported from Australia, and Central and South America. ${ }^{2-7}$ In addition to livestock, stable flies also attack wildlife, companion animals and humans.

The painful bites from these flies reduce livestock productivity and increase animal stress by disrupting feeding, reproductive, and resting behaviors..$^{8-12}$ They are considered significant economic pests in many parts of the world. ${ }^{1,13,14}$ Taylor et al. ${ }^{15}$ estimated that stable flies reduce cattle productivity in the U.S. by over $\$ 2$ billion per year.

Although not currently considered to be a major vector of livestock disease in North America, stable flies are involved in the transmission of several important diseases including trypanosomiasis and lumpy skin disease (Capripox) ${ }^{16}$ elsewhere in the world. Recently, Olesen et al. ${ }^{17}$ reported that one of the most important invasive livestock diseases in Europe, African Swine Fever, can be transmitted by stable flies through either the ingestion of infected flies, or via their bite. ${ }^{18}$ Previously, stable flies have been reported to transmit a wide variety of pathogens that are primary disease agents leading to cattle mortality. 1,19,20

* Correspondence to: JJ Zhu, USDA-ARS Agroecosystem Management Research Unit, USDA-ARS, University of Nebraska, East Campus, Lincoln, NE 68583, USA. E-mail:jerry.zhu@ars.usda.gov

a Agroecosystem Management Research Unit, Agricultural Research Service, U.S. Department of Agriculture, Lincoln, NE, USA

b Institute of Disinfection and Vector Control, Center for Disease Control and Prevention, Beijing, Beijing, China

c College of Life Science, China Jiliang University, Hangzhou, China

d U.S. Department of Agriculture, Agricultural Research Service, National Center for Agricultural Utilization Research, Peoria, IL, USA

e Department of Entomology, University of Nebraska, Lincoln, NE, USA

$\mathrm{f}$ Institute of Life Science (BK21+ Program)/Institute of Agriculture and Life Science, Gyeongsang National University, Jinju, Republic of Korea 
Current technologies to control adult stable flies are inadequate, laborious, and expensive. ${ }^{21-25}$ The use of botanically derived repellents or biopesticides is an alternative option for their management that is economically viable and environmentally safe. Zhu and coworkers ${ }^{26,27}$ have shown that essential oils derived from catnip (Nepeta cataria) and Geranium species exhibit strong repellency against biting flies, including stable fly. Zhu et al. ${ }^{28}$ also reported that stable fly larval growth and female oviposition was inhibited in developmental substrates treated with encapsulated catnip oil. However, due to the high volatility of the active compounds in these plant essential oils, the longevity of effectiveness was relatively short. Therefore, it is critical to discover additional plant-based repellents with extended residual activity. Recently, Zhu et al. ${ }^{29}$ demonstrated that medium chain fatty acids associated to coconut oil repel a broad array of blood-sucking arthropods. In the present study, we report further findings concerning spatial repellency and antifeedant activity of a bio-based product, coconut fatty acid, which mainly consists of free fatty acids of $\mathrm{C}_{8}: 0, \mathrm{C}_{10: 0}, \mathrm{C}_{12: 0}$, and their corresponding methyl esters derivatives against stable flies. Bio-pesticidal activities of these methyl ester derivatives are also discussed.

\section{MATERIALS AND METHODS}

\subsection{Stable fly sources and tested chemicals}

Stable flies used for laboratory tests were from colonies maintained at the U.S. Department of Agriculture, Agricultural Research Service, Agroecosystem Management Research Unit (Lincoln, NE, USA). The flies were maintained as described by Friesen et al. ${ }^{30}$

The coconut fatty acid (Coconut FFA) was a bio-based product hydrolyzed from the natural coconut oil, which converts triglycerides into free fatty acids. It was obtained from ACME-HARDESTY (Blue Bell, PA, USA). The coconut FFA consisted of caprylic acid, capric acid, lauric acid, myristic acid, palmitic acid, stearic acid, oleic acid and linoleic acid at a ratio of 6.85:7.33:52.68:17.14:8.44:1.29:6.02:0.34 (Zhu et al. ${ }^{29}$ ). Synthetic fatty acid standards $\left(C_{8: 0}, C_{10: 0}, C_{12: 0}\right)$ and 1-octen-3-ol were purchased from Sigma-Aldrich (St. Louis, MO, USA), with purity from 90-99\%, and methyl esters were synthesized as described by Zhu et al. ${ }^{29}$ Test compounds were diluted to desired concentrations with hexane or ethanol [Sigma-Aldrich (99-100\%)].

\subsection{Antennal responses to repellent compounds}

Electroantennograms (EAG) were recorded as indicated in Tangtrakulwanich et al. ${ }^{31}$ Each compound was diluted to $10 \mu \mathrm{g} \mu \mathrm{L}^{-1}$ using either hexane (Burdick \& Jackson High Purity Solvent). Neat solvent was used as the control stimulus. Antennae of $S$. calcitrans from 3-5 days old male and female adults were used. A piece $(0.5 \times 2.5 \mathrm{~cm})$ of filter paper (Whatman No.1, Whatman International Ltd., England) impregnated with $10 \mu \mathrm{L}$ aliquot of the above-mentioned test solution was inserted into a glass Pasteur pipette $(15 \mathrm{~cm}$ long) and used for odor presentation. For dose-response studies, selected repellent active compounds were diluted to $0.1,1,10$ and $100 \mu \mathrm{g} \mu \mathrm{L}^{-1}$.

Antennae were positioned approximately $1 \mathrm{~cm}$ from the outlet of the glass tube. For stimulation, $5 \mathrm{~mL}$ of purified air, was introduced through a charcoal-filtered Pasteur pipette cartridge (Syntech Auto-Puffer, Germany) for $0.5 \mathrm{~s}$ into the glass tube using a continuous humidified air stream flowing at $500 \mathrm{~mL} \mathrm{~min}^{-1}$. An electrically controlled airflow controller (CS-55, Syntech, Germany) was used for the stimulation. At least $30 \mathrm{~s}$ was allowed between successive stimulations and the stimulations with different odorants were made in random order. Catnip oil $(10 \mu \mathrm{g})$ was used as a standard stimulus in EAG tests to indicate the antennal activity and sensitivity (antennae that failed to respond to catnip were considered inactive and were discarded).

For dose-response experiments, exposure proceeded from the lowest to the highest concentration to minimize olfactory adaptation by overexposure. Test series for dose response were always preceded and followed by the standard stimulus and the standard stimulus was also applied after each dosage of the tested compound was completed. The wide end of the Pasteur pipette was covered with a piece of aluminum foil when not in use to reduce compound loss due to evaporation. Each odor stimulus cartridge was used three times. EAG responses were measured from antennae of five males and five females.

Electrophysiological responses were analyzed by analysis of variance (ANOVA) and means were separated by least significant difference (LSD) test. Statistical analyses were performed using SAS 9.3 (SAS institute, Cary, NC, USA).

\subsection{Laboratory feeding bioassay}

The laboratory bioassay for testing antifeeding activity used a 6-cell K\&D module ${ }^{32}$ with modifications for stable fly. ${ }^{26}$ Stable flies ( $3-4$ days old) were starved for $48 \mathrm{~h}$ prior to testing. Three doses of repellents $(2 \mathrm{mg}, 10 \mathrm{mg}$ and $20 \mathrm{mg}$ ) were dissolved in $200 \mu \mathrm{L}$ of hexane and then applied evenly onto the outer layers of $4 \times 5 \mathrm{~cm}$ paper towel (Kitchen Bounty, Procter \& Gamble Company, $\mathrm{OH}, \mathrm{USA}$ ). After air drying, the repellent-impregnated paper was placed on top of a bovine blood-soaked non-sterile absorbent ABD pad $(3.75 \times 4.75 \mathrm{~cm}$, Total Resources International, CA, USA) with about $3.5 \mathrm{~mL}$ of blood in each cell bed of the module. A control paper was treated with $200 \mu \mathrm{L}$ of only hexane. Four to five starved stable flies were transferred into each of the six testing cells by using a Pyrex glass pooter (self-made). After $4 \mathrm{~h}$ of exposure inside the cells, stable flies were anesthetized by placing them inside a $-10^{\circ} \mathrm{C}$ freezer for $5 \mathrm{~min}$ and the immobilized flies were checked for feeding status by squashing their abdomen to examine for the presence of blood. Repellent assays were conducted daily at room temperature. Flies in the repellent bioassay were exposed to randomized treatments (different repellents and dosages) and treatments were repeated until at least four to five replicates were completed. During the experiments, fly knockdown was recorded and mortality was observed. Immobile flies on the bottom of the module were considered dead.

Percentiles of repellency [(number of flies fed on control - number of flies fed in treatment)/number of flies fed on control $\times 100$ ] was determined and transformed to arcsine square-root values for analyses of variance (ANOVA). Significant differences at $P<0.05$ (SAS version 10; SAS Institute, Cary, NC, USA) were determined by analyses performed on the Least-Square Means due to the unequal number of observations among the treatments. Numbers of replicates and treatments tested were determined by the number of stable flies available per day and controls were always run simultaneously.

\subsection{Spatial repellent assay in the single cage olfactometer}

For each single cage, a dual port glass olfactometer was used to assess spatial repellency of test compounds for stable flies. ${ }^{33}$ Three to four day-old stable flies were starved for $48 \mathrm{~h}$ prior to testing. Five stable flies were released into the olfactometer in each group from the release port and given $5 \mathrm{~min}$ to respond; their presence in either repellent treated or control port $(>10 \mathrm{~cm}$ 

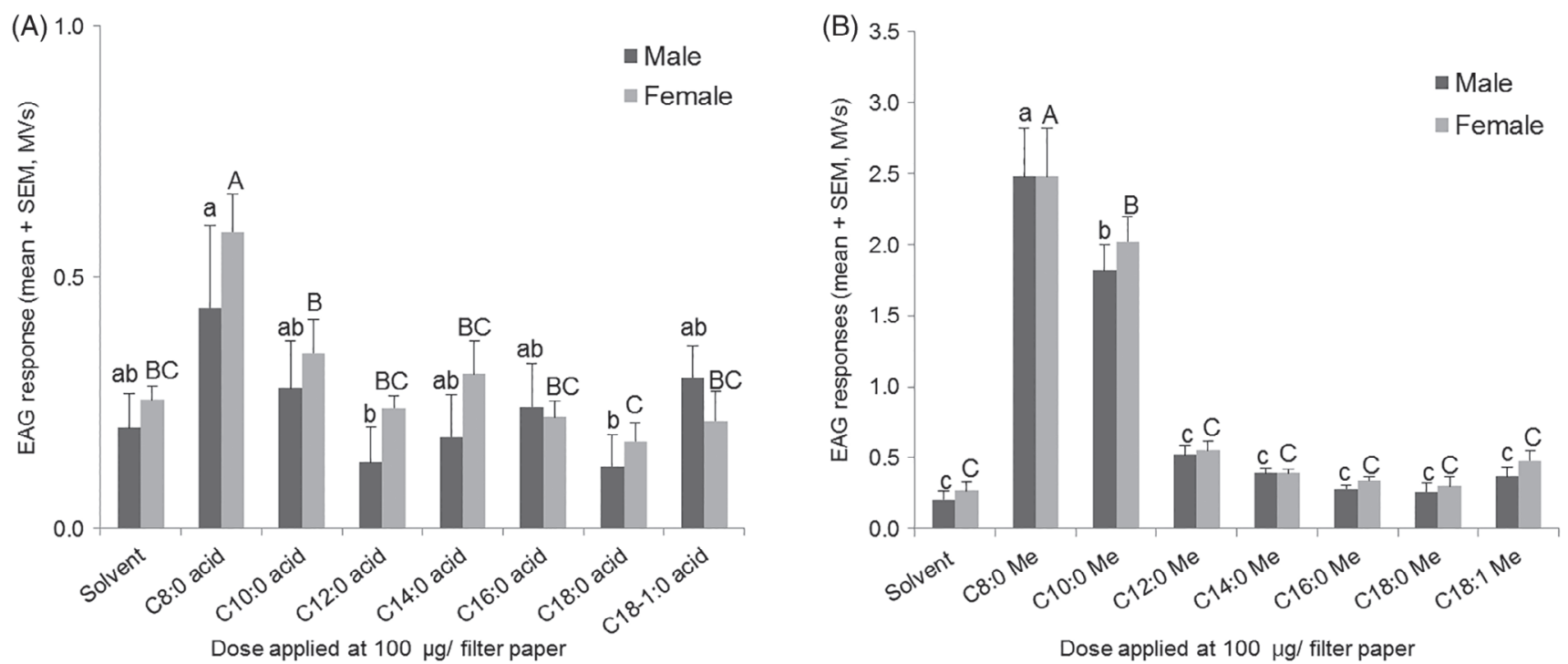

Figure 1. Electroantennogram response of $S$. calcitrans male and female antennae to $(A)$ fatty acids and $(B)$ their methyl esters $(N=5)$. Different letters above the bars indicate significant differences within the same sex (LSD, $P<0.05)$.

inside the port) was recorded. Normally, one set of the three dose tests (one treatment) was performed each day. Repellents were first dissolved in hexane to make solutions having concentrations of $10,50,100 \mu \mathrm{g} \mu \mathrm{L}^{-1}$. The repellent solution $(10 \mu \mathrm{L})$ was applied to a piece of filter paper (cut as a small triangle, $2 \mathrm{~cm}$ for each side). For the control, $10 \mu \mathrm{L}$ of hexane was applied. The filter paper was air dried, fixed to an insect pin, and placed in the middle of a test port of the olfactometer (hung from about $2-3 \mathrm{~cm}$ from the ceiling of the port). Within each set of tests, positions of the ports, repellents or control, was randomized. All three ports (including the release port) were cleaned with ethanol followed by acetone before and after each test. Each test was replicated 8-15 times, in which the port positions were changed (left to right) after half the replicates were completed. New flies were used for each replicate.

Responses were recorded as a percentage of flies inside the treatment or control ports. After checking the homogeneity of variance and normality of data, they were analyzed using Student $t$-tests and the generalized linear model (GLM) and means were separated by the Tukey's HSD test. Log transformations were done when necessary. Results with $P<0.05$ were considered statistically significant.

\subsection{Atmospheric concentrations of fatty acid and methyl ester measurements}

Atmospheric concentrations of fatty acids $\left(C_{8: 0}, C_{10: 0}\right.$ and $C_{12: 0}$ acid) and their corresponding methyl esters $\left(C_{8: 0}, C_{10: 0}\right.$ and $\mathrm{C}_{12: 0} \mathrm{Me}$ ) for the repellent/antifeedant activity bioassays were measured via solid-phase microextraction (SPME), in which the atmospheric concentrations of repellent compounds were compared with the SPME absorption rates after being analyzed in an Agilent gas chromatograph equipped with a DB-FFAP column (30 $\mathrm{m} \times 0.25 \mathrm{~mm}$ i.d., J \& W Scientific, Agilent). Peak areas of repellent compounds absorbed onto the fibers were analyzed through the thermo-desorption and further integrated by Agilent Chem-Station program. Helium was used as the carrier gas, and the flow rate maintained at $1.5 \mathrm{~mL} \mathrm{~min}{ }^{-1}$. Samples were injected under splitless mode. The temperature program for the $\mathrm{GC}$ analyses was set at $50^{\circ} \mathrm{C}$ for $3 \mathrm{~min}$, then ramped to $280^{\circ} \mathrm{C}$ for $10{ }^{\circ} \mathrm{C} \mathrm{min}^{-1}$. The $100 \mathrm{~mm}$ polydimethylsiloxane (PDMS) fibers (Supelco, St. Louis, MO, USA) were conditioned in an Agilent gas chromatograph (GC) inlet held at $250^{\circ} \mathrm{C}$ for $30 \mathrm{~min}$ before sampling. Each test sample (10 mg) was transferred into a $1.5 \mathrm{~mL}$ glass vial and sealed. The SPME fiber was exposed inside the vial for $20 \mathrm{~s}$ for fatty acids and $5 \mathrm{~s}$ for methyl esters (three replications of each chemical). The absorption rates of fatty acids and methyl esters on SPME fibers were quantified by comparing with the peak areas of synthetic acid and methyl ester standards based on their established standard curves. Each chemical standard was weighed using an analytical balance with a readability of $0.01 \mathrm{mg}$ (Mettler, Toledo AL104, Ohio, USA), and then subsequently dissolved to the desired concentration in hexane. Six-point calibration curves to determine linearity were obtained for each chemical at concentrations ranging from $31.5,62.5,125,250,500$, and $1000{\mathrm{ng} \mu \mathrm{L}^{-1}}^{-1}$ with three replications per concentration. Linearity was assumed when the regression coefficient provided an $R^{2}>0.85$.

\section{RESULTS}

\subsection{Antennal responses}

Antennal responses of both male and female stable flies were measured when stimulated with the major fatty acids $\left(C_{8: 0}\right.$ to $C_{18: 1}$ ) contained in coconut FFA and their corresponding methyl esters (Fig. 1). For the fatty acid series, female stable flies expressed elevated EAG responses to the $C_{8: 0}$ fatty acid $(d f=7,32 ; F=6.43$; $P<0.0001$, Fig. 1(a)). EAG responses to all other tested fatty acids from male antennae were not significantly different from the solvent control ( $d f=7,32 ; \mathrm{F}=1.28 ; P=0.2922)$. However, for the methyl ester (Me) series, elevated EAG responses were observed to $\mathrm{C}_{8: 0}$ Me and $\mathrm{C}_{10: 0}$ Me for both male and female stable fly antennae (male: $\mathrm{df}=9,40 ; \mathrm{F}=17.13 ; P<0.0001$, female: $\mathrm{df}=9,40 ; \mathrm{F}=37.53$; $P<0.0001$, Fig. 1(b)).

Coconut FFA is comprised of a total of eight acids with three dominating medium chain fatty acids, octanoic acid, decanoic acid, and lauric acid. EAG dose-response tests to these three fatty acids and their methyl ester derivatives were also conducted (Fig. 2). Only female EAG responses to the octanoic acid increased gradually as the dose increased, and the response peaked at 

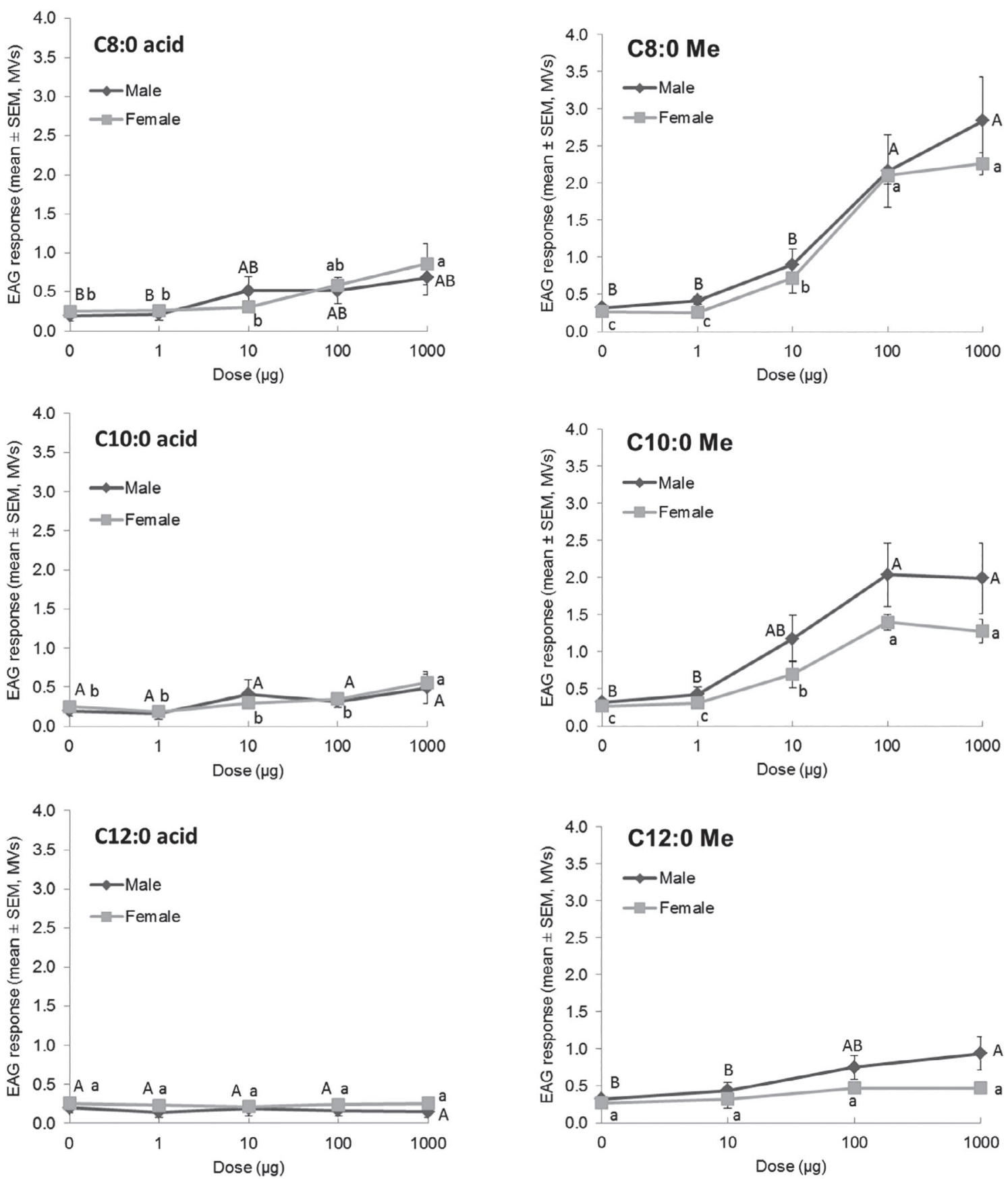

Figure 2. EAG dose-response of $S$. calcitrans male and female antennae to main chain fatty acids and their methyl esters $(N=5)$. Dose indicates the amount of compound $(\mu \mathrm{g})$ loaded onto a piece of filter paper in a Pasteur pipette odor cartridge. Different letters above the bars indicate significant differences within the same sex (LSD, $P<0.05)$.

$1000 \mu \mathrm{g}$ dose (male: $\mathrm{df}=4,20 ; \mathrm{F}=1.89 ; P=0.1516$, female: $\mathrm{df}=4$, $20 ; F=4 ; P=0.0152$ ). Similar results were also found in female antennae to the decanoic acid (male: $\mathrm{df}=4,20 ; \mathrm{F}=0.99 ; P=0.437$, female: $\mathrm{df}=4,20 ; \mathrm{F}=4.73 ; P=0.0075)$. But, no differences were found in EAG responses to lauric acid at all three doses tested from both sexes of stable fly adults.

In contrast, EAG responses to all three methyl esters were significantly higher than those to the corresponding acids. Among the three methyl esters tested, significantly higher EAG responses to the $C_{8: 0}$ Me and $C_{10: 0}$ Me were elicited when the tested dose was $>100 \mu \mathrm{g}$ in males $\left(C_{8: 0}\right.$ Me: $\mathrm{df}=4,20 ; \mathrm{F}=9.89 ; P<0.0001, C_{10: 0}$ Me: $\mathrm{df}=4,20 ; \mathrm{F}=6.57 ; P<0.005)$. For females, $\mathrm{C}_{8: 0} \mathrm{Me}$ and $\mathrm{C}_{10: 0} \mathrm{Me}$ elicited significantly higher antennal responses starting at a dose as low as $10 \mu \mathrm{g}\left(\mathrm{C}_{8: 0} \mathrm{Me}: \mathrm{df}=4,20 ; \mathrm{F}=53.03 ; P<0.0001, \mathrm{C}_{1000} \mathrm{Me}\right.$ : $\mathrm{df}=4,20 ; \mathrm{F}=17.43 ; P<0.0001)$. However, for the $C_{12.0}$ Me, only the highest dose, $1000 \mu \mathrm{g}$, elicited significant EAG responses in males $(\mathrm{df}=3,16 ; \mathrm{F}=3.68 ; P<0.05)$.

When coconut FFA was examined, significant EAG responses were elicited starting from $100 \mu \mathrm{g}$ dose for female antennae $(\mathrm{df}=3$, $16 ; \mathrm{F}=32.39 ; P<0.0001$ ), and for male antennae only the highest dose, $1000 \mu \mathrm{g}$, elicited significant EAG responses $(\mathrm{df}=3,16 ; \mathrm{F}=3.3$; $P<0.05$ ) (Fig. 3). 


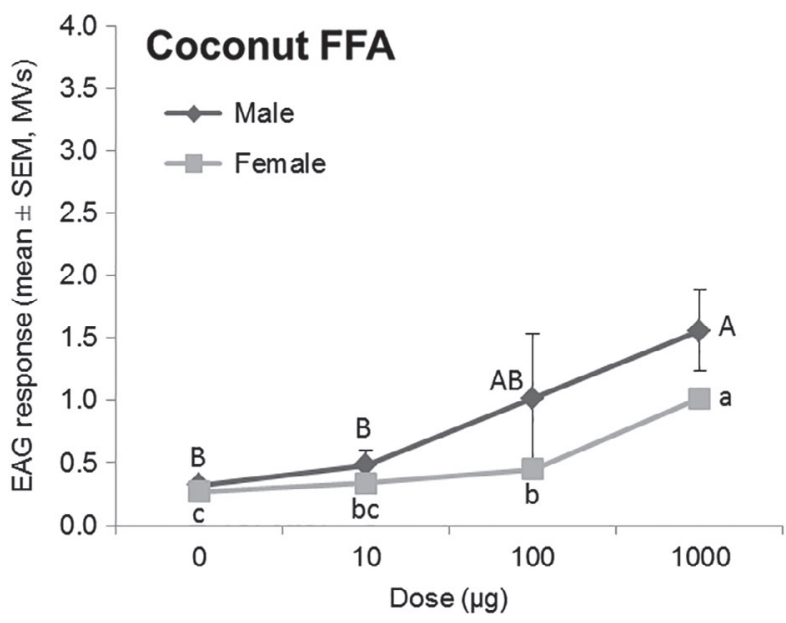

Figure 3. EAG dose-response of $S$. calcitrans male and female antennae to coconut FFA $(\mathrm{N}=5)$. Dose indicates the amount of compound $(\mu \mathrm{g})$ loaded onto a piece of filter paper in a Pasteur pipette odor cartridge. Different letters above the bars indicate significant differences within the same sex $(\mathrm{LSD}, P<0.05)$

\subsection{Spatial repellency of fatty acids and methyl esters to stable flies}

The single cage olfactometer bioassay showed that spatial repellency was only observed at the highest dose $(1000 \mu \mathrm{g})$ of the coconut FFA $(\mathrm{df}=18 ; \mathrm{t}$ value $=2.27 ; P<0.05$, Table 1$)$. For the three individual fatty acids $\left(C_{8: 0}, C_{10: 0}\right.$ and $\left.C_{12: 0}\right)$, spatial repellency was not observed at any of the dosages tested. While testing stable fly responses to methyl esters, only $\mathrm{C}_{8: 0} \mathrm{Me}$ at a dose of $100 \mu \mathrm{g}$ showed significant spatial repellency $(\mathrm{df}=14 ; \mathrm{t}$-value $=2.44 ; P<0.05)$.
In contrast, the $500 \mu \mathrm{g}$ dose was attractive to stable flies ( $\mathrm{df}=18$; $\mathrm{t}$-value $=-2.29 ; P<0.05)($ Table 1$)$.

We further examined stable fly responses using a previously reported attractant (1-octen-3-ol $\left.{ }^{34}\right)$ with additions of the spatial repellent compounds mentioned above to see whether the attraction would be inhibited (Table 2). Neat 1-Octen-3-ol at $1000 \mu \mathrm{g}$ was observed to be attractive to stable flies ( $\mathrm{df}=28$; $\mathrm{t}$-value $=2.15, P<0.05$ ), but, when $100 \mu \mathrm{g}$ of the $C_{8: 0}$ Me or $1000 \mu \mathrm{g}$ of coconut FFA was added to the attractant, stable flies were strongly repelled $(\mathrm{df}=18 ; \mathrm{t}$-value $=2.58 ; P<0.05$ and $\mathrm{df}=18$; $\mathrm{t}$-value $=2.19 ; P<0.05$, respectively).

Atmospheric concentrations of $C_{8: 0}, C_{10: 0}$ and $C_{12: 0}$ fatty acids and methyl esters were compared by examining the absorption rates of those chemicals onto the SPME fibers. The analyses revealed that significant differences in SPME absorption rates were found from three fatty acids measured, but none from the methyl esters. The mean absorption rates for fatty acids were $10.2 \mathrm{ng} \mathrm{min}^{-1}\left(C_{8: 0}\right.$ acid), $5.9 \mathrm{ng} \mathrm{min}^{-1}\left(\mathrm{C}_{10: 0}\right.$ acid) and $4.2 \mathrm{ng} \mathrm{min}^{-1}$ ( $C_{12: 0}$ acid), respectively. However, average absorption rates for three methyl esters were similar, ranging from 9.4 to $11.0 \mathrm{ng} \mathrm{min}^{-1}$.

\subsection{Antifeedant assay}

In antifeedant activity tests of the methyl esters of acids from $C_{8: 0}$ to $\mathrm{C}_{18: 0}$, only $\mathrm{C}_{8: 0}$ Me, $\mathrm{C}_{10: 0}$ Me and $\mathrm{C}_{12: 0}$ Me deterred stable fly blood feeding (Fig. 4(a)). In the corresponding dose-response tests, all three medium chain methyl esters exhibited high feeding inhibition ( $d f=2 ; F=6.7 ; P<0.05 ;$ Fig. $4(b))$, with over $90 \%$ of stable flies found no blood-feeding when tested at the 10 and $20 \mathrm{mg}$ dosages (Fig. $4(\mathrm{~b})$ ). $\mathrm{C}_{8: 0}$ Me and $\mathrm{C}_{10: 0}$ Me showed stronger antifeedant activity against stable flies, compared to $C_{12: 0} M e .(d f=2 ; F=23.7$; $P<0.0001)$. At the $2 \mathrm{mg}$ dosage, no or low antifeedant activity was found from the three methyl esters.

Table 1. Spatial repellency of coconut oil free fatty acids, three compositional medium chain fatty acids $\left(C_{8: 0}, C_{10: 0}, C_{12: 0}\right)$ and their methyl esters in a single cage olfactometer against stable flies, Stomoxys calcitrans

\begin{tabular}{|c|c|c|c|c|c|}
\hline Functional group & Compound & Dose $(\mu \mathrm{g})$ & Treatment (\%) & Control (\%) & Significance \\
\hline \multirow[t]{12}{*}{ Fatty acids } & \multirow[t]{3}{*}{$C_{8: 0}$ acid } & 100 & $62 \pm 7.6$ & $38 \pm 7.4$ & 0.0785 \\
\hline & & 500 & $49 \pm 9.0$ & $51 \pm 8.8$ & 0.9388 \\
\hline & & 1000 & $44 \pm 6.1$ & $56 \pm 6.1$ & 0.2182 \\
\hline & \multirow[t]{3}{*}{$C_{10: 0}$ acid } & 100 & $56 \pm 5.5$ & $44 \pm 5.3$ & 0.1231 \\
\hline & & 500 & $49 \pm 7.6$ & $51 \pm 7.4$ & 0.6805 \\
\hline & & 1000 & $55 \pm 6.7$ & $45 \pm 6.7$ & 0.5240 \\
\hline & \multirow[t]{3}{*}{$C_{12: 0}$ acid } & 100 & $55 \pm 8.9$ & $45 \pm 8.7$ & 0.7285 \\
\hline & & 500 & $44 \pm 9.9$ & $56 \pm 9.7$ & 0.8386 \\
\hline & & 1000 & $52 \pm 5.4$ & $48 \pm 5.4$ & 0.7064 \\
\hline & \multirow[t]{3}{*}{ Coconut FFA } & 100 & $46 \pm 7.8$ & $54 \pm 7.6$ & 0.3595 \\
\hline & & 500 & $47 \pm 5.2$ & $53 \pm 5.0$ & 0.4376 \\
\hline & & 1000 & $39 \pm 6.6$ & $61 \pm 6.6$ & $0.0360^{*}$ \\
\hline \multirow[t]{9}{*}{ Esters } & \multirow[t]{3}{*}{$\mathrm{C}_{8: 0} \mathrm{Me}$} & 100 & $29 \pm 8.9^{*}$ & $71 \pm 8.9$ & $0.0287^{*}$ \\
\hline & & 500 & $65 \pm 8.3^{*}$ & $35 \pm 8.3$ & $0.0343^{*}$ \\
\hline & & 1000 & $59 \pm 8.9$ & $41 \pm 8.9$ & 0.1348 \\
\hline & \multirow[t]{3}{*}{$\mathrm{C}_{10: 0} \mathrm{Me}$} & 100 & $57 \pm 10.7$ & $43 \pm 10.7$ & 0.4342 \\
\hline & & 500 & $52 \pm 11.5$ & $48 \pm 11.5$ & 0.8856 \\
\hline & & 1000 & $58 \pm 9.0$ & $42 \pm 9.0$ & 0.5634 \\
\hline & \multirow[t]{3}{*}{$\mathrm{C}_{12: 0} \mathrm{Me}$} & 100 & $56 \pm 8.9$ & $44 \pm 8.9$ & 0.3040 \\
\hline & & 500 & $44 \pm 10.3$ & $56 \pm 10.3$ & 0.1521 \\
\hline & & 1000 & $60 \pm 6.5$ & $40 \pm 6.5$ & 0.1101 \\
\hline
\end{tabular}

*Indicate a significant difference between the treatments and control ( $t$-test at $P=0.05$ ). No significant differences were found among the three acids and esters tested in both doses and different treatments (Tukey's HSD at $P=0.05$ ). 
Table 2. Behavioral inhibition of stable fly orientation to the attractant source by adding selected repellent compounds in a single cage olfactometer

\begin{tabular}{|c|c|c|c|}
\hline \multirow[b]{2}{*}{ Comparison-1 } & \multicolumn{3}{|c|}{ Response (\%) } \\
\hline & 1-octen-3-ol $(1000 \mu \mathrm{g})$ & Blank & Significance \\
\hline \multirow{3}{*}{ Comparison-2 } & $61 \pm 5.9$ & $39 \pm 5.9$ & $0.0401^{*}$ \\
\hline & 1-octen-3-ol $(1000 \mu \mathrm{g})+\mathrm{C}_{8: 0} \mathrm{Me}(100 \mu \mathrm{g})$ & 1-octen-3-ol $(1000 \mu \mathrm{g})$ & \\
\hline & $34 \pm 6.9$ & $66 \pm 6.7$ & $0.0188^{*}$ \\
\hline \multirow[t]{2}{*}{ Comparison-3 } & 1-octen-3-ol $(1000 \mu \mathrm{g})+$ Coconut FFA $(1000 \mu \mathrm{g})$ & 1-octen-3-ol $(1000 \mu \mathrm{g})$ & \\
\hline & $35 \pm 6.3$ & $65 \pm 6.2$ & $0.0416^{*}$ \\
\hline
\end{tabular}
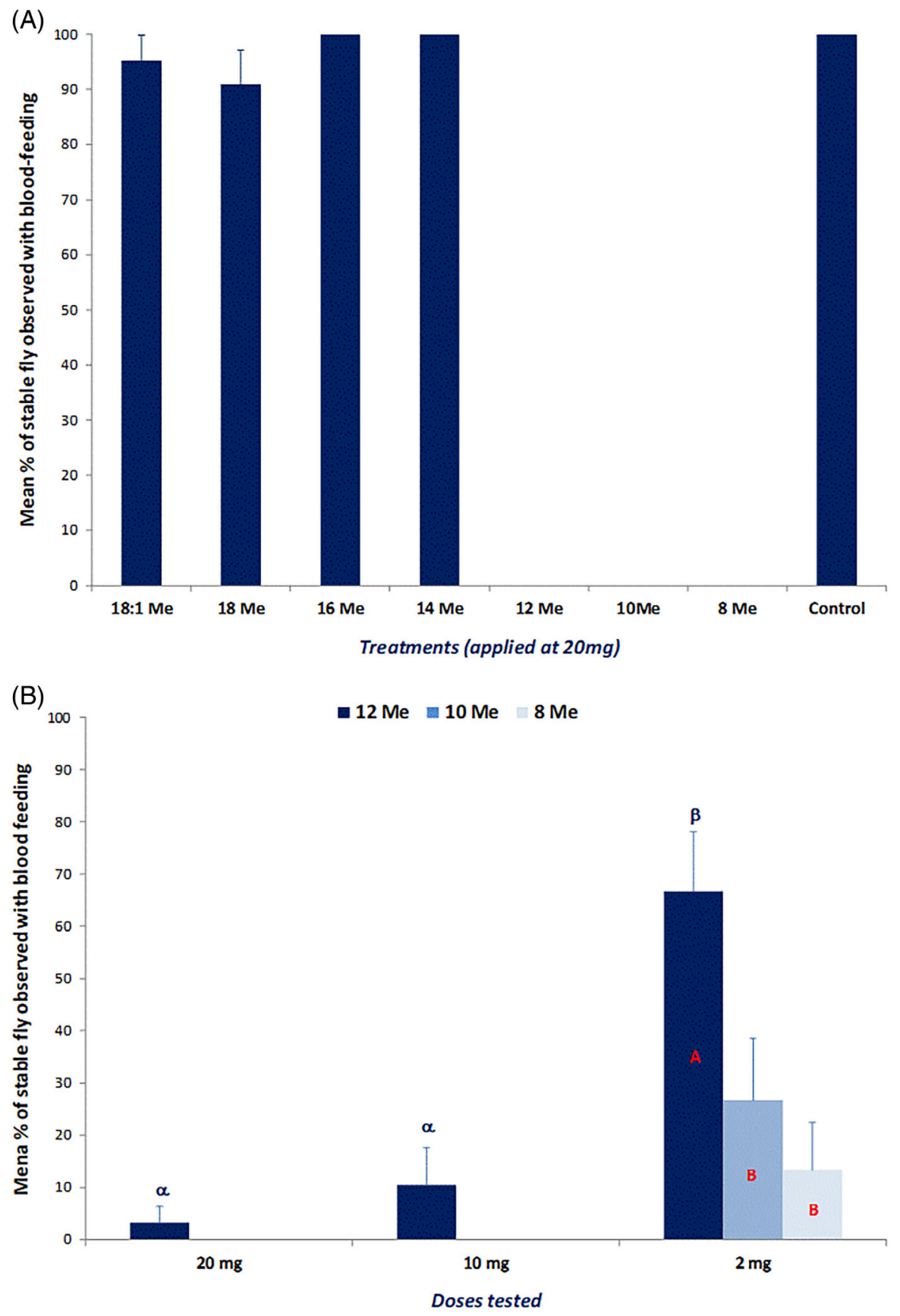

Figure 4. (A) Percentage of blood-feeding observed from 48-h starved stable flies (Stomoxy calcitrans) with $\mathrm{C}_{8}$ to $\mathrm{C}_{18}$ methyl ester treatments from modified lab behavioral K\&D assays. (B) Mean \% of stable fly blood-feeding using three fatty acid methyl esters at three doseage concentrations. Different symbol letters on top of bars indicate significant differences at a dose of $20 \mathrm{mg}$ (ANOVA, followed by Scheffe tests, $P<0.005$ ), and inside the bars different letters indicate significant difference of three methyl esters at $2 \mathrm{mg}$ (ANOVA, followed by Scheffe tests, $P<0.001$ ). Error bars show standard errors of the means. 

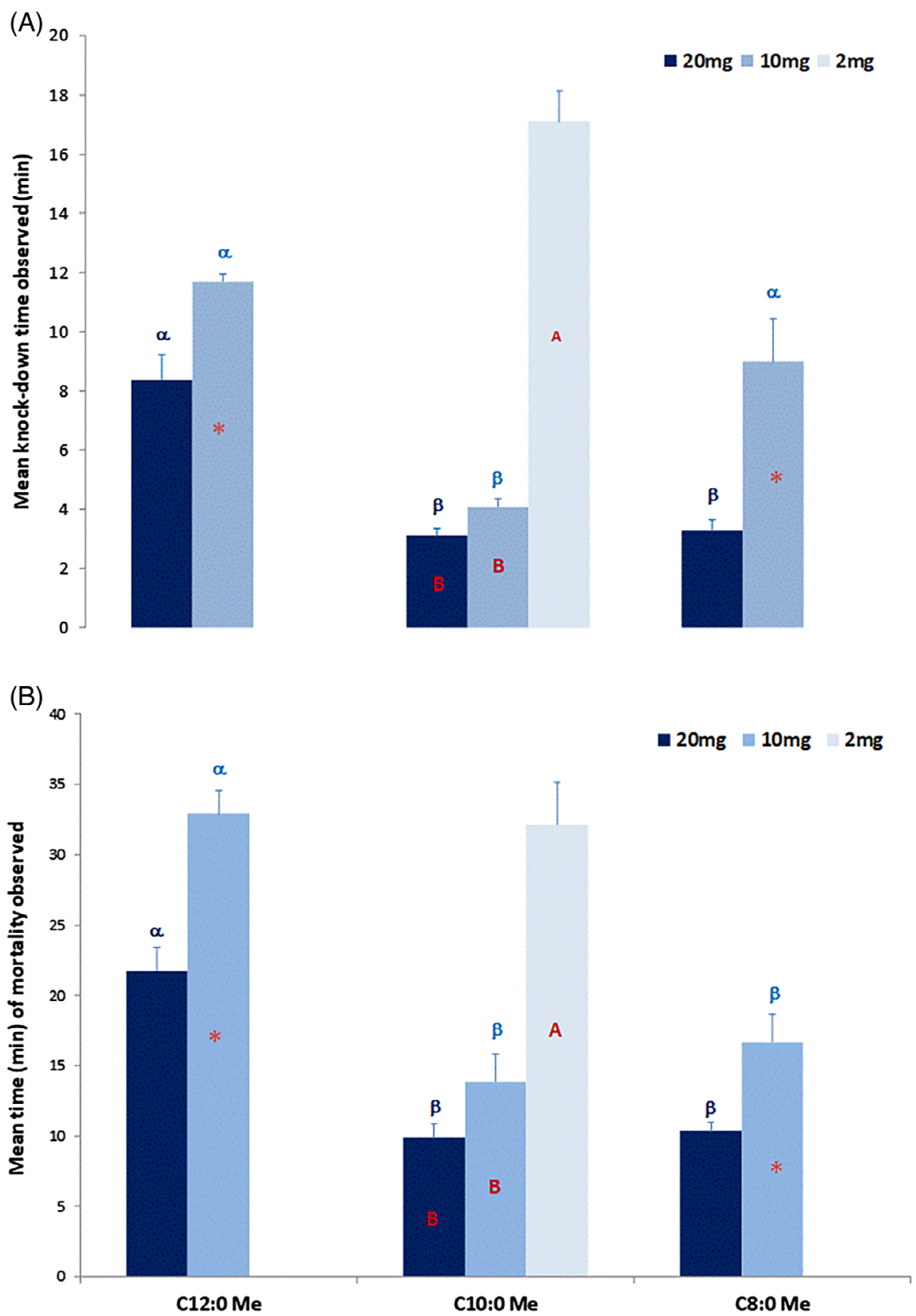

Figure 5. (A) The stable fly knock-down times by the three fatty acid methyl esters at three doses. (B) Mortality observed at the time of exposure of fatty acid methyl esters at three doses. Different symbol letters on top of bars indicate significant differences among treatments (ANOVA, followed by Scheffe tests, $P<0.05)$, and different letters and asterisks inside the bars indicate significant differences among treatments $\left(C_{10: 0}\right.$ Me, ANOVA, followed by Scheffe tests, $P<0.05 ; C_{8: 0} M e$ and $C_{12: 0}$ Me: T-test $\left.P<0.05\right)$. Error bars show standard errors of the means.

\subsection{Toxicity (Knock-down and mortality)}

While testing methyl esters in blood-feeding tests, we also observed that the stable flies were being 'knocked down' quickly and died around 10 min after knock-down. Knock-down times differed among three methyl esters and in different doses (Fig. 5). At the 10 and $20 \mathrm{mg}$ dosages, $\mathrm{C}_{10: 0}$ Me knocked stable flies down faster ( $<5 \mathrm{~min})$, compared with the other esters $(\mathrm{df}=2 ; \mathrm{F}=12.1$; $P<0.0001$ and $d f=2 ; F=26.8 ; P<0.0001$, respectively) (Fig. 5(a)). At the lowest dose, $2 \mathrm{mg}$, knock-down of stable flies was only observed with $C_{10: 0}$ Me with a much longer knock down time of over 17 min needed.
The times needed for a $100 \%$ mortality were also calculated (Fig. 5(b)). The times of $100 \%$ mortality for stable flies exposed to $\mathrm{C}_{12: 0} \mathrm{Me}$ at two higher doses (10 and $20 \mathrm{mg}$ ) were significantly longer than those from $C_{10: 0}$ Me and $C_{8: 0}$ Me $(d f=2 ; F=11.1$; $P<0.005$ and $\mathrm{df}=2 ; \mathrm{F}=34.3 ; P<0.0001$, respectively). The times for $100 \%$ mortality decreased as the dosages of methyl esters increased. Almost all stable flies were knocked down when treated with methyl esters at $10 \mathrm{mg}$ and $20 \mathrm{mg}$. When tested at $2 \mathrm{mg}$, only $\mathrm{C}_{10: 0}$ Me was able to knock stable flies down, with approximately $80 \%$ of tested flies observed on the bottom of the cell. However, the mortality among those flies was only at $32 \pm 9 \%$. 
The mean percentages of mortality from two higher doses $(10 \mathrm{mg}$ and $20 \mathrm{mg}$ ) of three methyl esters were from $85 \%$ to $100 \%$, respectively.

\section{DISCUSSION AND CONCLUSION}

The stable fly, Stomoxys calcitrans, is primarily considered to be the most serious livestock pest found in feedlot, barns, and pasture environments. ${ }^{35}$ Furthermore, stable fly outbreaks associated with agronomic production in the past 10 years have caused infestation levels greatly exceeding 1000 flies per animal, which leads to high mortality rates among livestock. Especially in urban areas, this extends to companion animals. ${ }^{6}$ Stable flies are extremely difficult to manage since they are very adaptable. The larvae can develop in a broad variety of decomposing vegetative materials and current options to control stable flies are limited. Sanitation is the most commonly recommended method for managing stable flies. ${ }^{36}$ However, it is labor intensive. ${ }^{4}$ Plant derivatives with insecticidal and repellent properties, which have been known for at least two millennia, have been suggested as effective alternatives against biting insects, ${ }^{37-40}$ particularly since they may offer economically viable and environmentally safe options for developing advanced integrated stable fly management strategies to reduce cattle stress.

Several botanical-based repellents including catnip oil, geraniol oil, lemongrass oil, and short chain fatty acids are capable of repelling biting flies including stable flies on livestock. ${ }^{26,33,41-44}$ Unfortunately, this repellency lasts relatively briefly in effectiveness due to high volatility. ${ }^{33,45}$ Also, some of these essential oils are relatively expensive, rendering them impractical for control of biting flies on livestock. Recently, we identified several medium chain-length fatty acids derived from coconut oil that deter stable flies from blood-feeding and retain their repellency up to 2 weeks under laboratory conditions and 4-5 days in the field. ${ }^{29}$ However, coconut FFA exhibits only limited spatial repellency toward stable flies at higher doses, ${ }^{28,46}$ which indicates that the mechanism of antifeeding activity may result primarily due to contact deterrence rather than spatial repellency.

The results of stable fly EAG responses to $C_{8}$ to $C_{18}$ fatty acids support our above hypothesis. Among all fatty acids tested, only the $C_{8: 0}$ fatty acid elicited significant EAG responses from female stable fly antennae. Further measurements of the atmospheric concentrations from these fatty acids and their methyl esters demonstrated twice the SPME absorption rates from the $C_{8: 0}$ fatty acid than those from $C_{10: 0}$ and $C_{12: 0}$ fatty acids. However, the $C_{8: 0}$ fatty acid's atmospheric concentration $\left(10 \mathrm{ng} \mathrm{min}^{-1}\right)$ is still significantly lower than that of catnip oil ( $\left.154 \mathrm{ng} \mathrm{min}^{-1}\right)$, which also explains why the spatial repellency of the fatty acids is significantly lower compared to catnip oil. ${ }^{33}$ While testing the coconut FFA at the highest dose $(1 \mathrm{mg})$, spatial repellency against stable flies was observed. This was also supported by the significantly higher EAG responses elicited from stable fly antennae (over $1.5 \mathrm{mV}$ ) to the coconut FFA compared to those from individual fatty acids (0.25-0.6 mV), which could be explained due to some synergistic effects of the acid mixture.

One interesting observation from our animal topical application trials is that the sprayable coconut FFA ( $16 \%$ formulation) is toxic to other co-existing biting flies, horn flies (Boxler, personal communication). However, our laboratory assays have demonstrated that the coconut FFA acts as a strong feeding deterrent, rather than a toxic insecticide to stable flies. ${ }^{29} \mathrm{C}_{9: 0}$ and $\mathrm{C}_{11: 0}$ fatty acids do possess some levels of toxicity (Zhu unpublished). A strong repellent with toxicity may provide more effective control on stable flies. Furthermore, medium chain fatty acids are reported to be corrosive and present with an irritating odor, which is considered as unpleasant to humans. ${ }^{47}$ Interestingly, corresponding methyl esters $\left(\mathrm{C}_{8: 0} \mathrm{Me}\right.$, $\mathrm{C}_{10: 0} \mathrm{Me}$ and $\mathrm{C}_{12: 0} \mathrm{Me}$ ) are not corrosive and some also have fruity and orange-like odors that are more acceptable. ${ }^{48,49}$ Many naturally derived products of triglyceride oils have been widely used as the main component of pesticides. ${ }^{50} \mathrm{Hu}$ and Somuah ${ }^{51}$ recently reported pesticidal activity from $\mathrm{C}_{10: 0}$ Me extracted from hot pepper. After having tested antifeedant activity of the methyl esters from $C_{8}$ to $C_{18}$, we found that only the three medium chain fatty acid methyl esters $\left(C_{8: 0}, C_{10: 0}\right.$ and $\left.C_{12: 0}\right)$ demonstrated antifeedant activity. The effectiveness of the three esters was shown to correspond to their carbon chain lengths, with the strongest antifeeding activity found for the $C_{8: 0}$ Me. Relatively higher toxicities of $C_{8: 0}$ and $C_{10: 0}$ methyl esters are observed with less than 10 min required for $100 \%$ of mortality, which can be useful to develop a repellent formulation with additional toxic activity against stable flies. In addition, medium chain fatty methyl esters are considered as antimicrobial agents and have been reportedly exhibited antimicrobial activity for oral organisms. ${ }^{52,53}$ This may add additional benefits helping cattle to battle diseases transmitted by insects. ${ }^{54-56}$

In conclusion, three medium chain fatty acid methyl esters were demonstrated to have strong blood-feeding deterrence against stable flies. They also displayed significant toxic activity to stable fly adults. These findings are important in the development of more powerful stable fly repellent formulations, not only with efficient antifeeding activity, but also possessing strong toxicities to kill flies as further contact occurs. However, further field studies examining longevity of antifeeding activity and animal safety of sprayable formulations containing these methyl esters are necessary.

\section{ACKNOWLEDGEMENTS}

We express our deep gratitude to B. Voelker and Dennis Berkebile for their technical help with this study. This work was done in cooperation with the Institute of Agriculture and Natural Resources, University of Nebraska-Lincoln, and supported partly by the funding from USDA-NIFA grant (2017-70006-27207) and USDA-Innovation Fund (792-0142-701,016).

\section{REFERENCES}

1 Zumpt F, The Stomoxyine Biting Flies of the World:Diptera, Muscidae; Taxonomy, Biology, Economic Importance and Control Measures. Gustav Fischer Verlag, Stuttgart (1973).

2 Herrero MV, Montes L, Sanabria C, Sánchez A and Hernández R, Estudio inicial sobre la mosca de los establos Stomoxys calcitrans (Diptera: Muscidae), en la región del Pacífico Sur de Costa Rica. Cienc Vet (Heredia Costa, Rica) 11:11-14 (1989).

3 Herrero MV, Montes-Pico L and Hernández R, Abundancia relativa de Stomoxys calcitrans (L.) (Diptera: Muscidae) en seis localidades del Pacífico Sur de Costa Rica. Rev Biol Trop 39:309-310 (1991).

4 Cook DF, Dadour IR and Keals NJ, Stable fly, house fly (Diptera: Muscidae), and other nuisance fly development in poultry litter associated with horticultural crop production. J Econ Entomol 92:1352-1357 (1999).

5 Koller WW, Catto JB, Bianchin I, Soares CO, Paiva F, Tavares LER et al., Surtos da mosca-dos-estábulos, Stomoxys calcitrans, em Mato Grosso do Sul: novo problema para as cadeias produtivas da carne e sucroalcooleira? (Documentos 175). Embrapa Gado de Corte, Campo Grande, pp. $1-31$ (2009). 
6 Solórzano J-A, Gilles J, Bravo O, Vargas C, Gomez-Bonilla Y, Bingham G et al., Biology and trapping of stable flies (Diptera: Muscidae) developing in pineapple residues (Ananas comosus) in Costa Rica. J Insect Sci 15:145 (2015).

7 Dominghetti TFS, de Barros ATM, Soares CO and Cançado PHD, Stomoxys calcitrans (Diptera: Muscidae) outbreaks: current situation and future outlook with emphasis on Brazil [Surtos por Stomoxys calcitrans (Diptera: Muscidae) no Brasil: Situação atual e perspectivas]. Rev Bras Parasitol Vet 24:387-395 (2015).

8 Campbell JB, White RG, Wright JE, Crookshank R and Clanton DC, Effects of stable flies on weight gains and feed efficiency of calves on growing or finishing rations. J Econ Entomol 70:592-594 (1977).

9 Stork MG, The epidemiological and economic importance of fly infestation of meat and milk producing animals in Europe. Vet Rec 105:341-343 (1979).

10 Fraser AF and Broom DM, Cattle welfare problems, in Farm Animal Behaviour and Welfare, ed. by Fraser AF. Bailliere-Tindall, London, pp. 350-357 (1990).

11 Catangui MA, Campbell JB, Thomas GD and Boxler DJ, Calculating economic injury levels for stable flies (Diptera: Muscidae) on feeder heifers. J Econ Entomol 90:6-10 (1997).

12 Campbell JB, Skoda SR, Berkebile DR, Boxler DJ, Thomas GD, Adams DC et al., Effects of stable flies (Diptera: Muscidae) on weight gains of grazing yearling cattle. J Econ Entomol 94:780-783 (2001).

13 Mullens BA, Meyer JA and Bishop SE, Stable fly activity on California dairies. Calif Agric 42:20-21 (1988).

14 Masmeatathip R, Gilles J, Ketavan C and Duvallet G, First survey of seasonal abundance and daily activity of Stomoxys spp. (Diptera: Muscidae) in Kamphaengsaen campus, Nakornpathom Province, Thailand. Parasite 13:245-250 (2006).

15 Taylor DB, Moon RD and Mark DR, Economic impact of stable flies (Diptera: Muscidae) on dairy and beef cattle production. $J$ Med Entomol 49:198-209 (2012).

16 Baldacchino F, Muenworn V, Desquesnes M, Desoli F, Charoenviriyaphap T and Duvallet G, Transmission of pathogens by Stomoxys flies (Diptera, Muscidae): a review. Parasite 20:26 (2013a).

17 Olesen AS, Hansen MF, Rasmussen TB, Belsham GJ, Bødker R and Bøtner A, Survival and localization of African swine fever virus in stable flies (Stomoxys calcitrans) after feeding on viremic blood using a membrane feeder. Vet Microbiol 222:25-29 (2018).

18 Mellor PS, Kitching RP and Wilkinson PJ, Mechanical transmission of capripoxvirus and African swine fever virus by Stomoxys calcitrans. Res Vet Sci 43:109-112 (1987).

19 Buxton BA, Hinkle NC and Schultz RD, Role of insects in the transmission of bovine leukosis virus: potential for transmission by stable flies, horn flies, and tabanids. Am J Vet Res 46:123-126 (1985).

20 D'Amico F, Gouteux JP, Le Gall F and Cuisance D, Are stable flies (Diptera: Stomoxyinae) vectors of Trypanosoma vivax in the Central African Republic? Vet Res 27:161-170 (1996).

21 Hogsette JA and Ruff JP, Evaluation of flucythrinate- and fenvalerate-impregnated ear tags and permethrin ear tapes for fly (Diptera: Muscidae) control on beef and dairy cattle in Northwest Florida. J Econ Entomol 79:152-157 (1986).

22 Broce A, DeRouchey JM, Harner JP and Zurek L, Managing stable fly production at pasture feeding sites. KSU Ag Exp Sta Coop Ext Serv:1-2 (2005a).

23 Broce $A B$, Hogsette $J$ and Paisley $S$, Winter feeding sites of hay in round bales as major developmental sites of Stomoxys calcitrans (Diptera: Muscidae) in pastures in spring and summer. J Econ Entomol 98:2307-2312 (2005b).

24 Foil LD and Younger CD, Development of treated targets for controlling stable flies (Diptera: Muscidae). Vet Parasitol 137:311-315 (2006).

25 Hogsette JA, Nalli A and Foil LD, Evaluation of different insecticides and fabric types for development of treated targets for stable fly (Diptera: Muscidae) control. J Econ Entomol 101:1034-1038 (2008).

26 Zhu JJ, Zeng X-P, Berkebile D, Du H-J, Tong Y and Qian K, Efficacy and safety of catnip (Nepeta cataria) as a novel filth fly repellent. Med Vet Entomol 23:209-216 (2009).

27 Zhu JJ, Li A, Pritchard S, Tangtrakulwanich K, Baxendale F and Brewer G, Contact and fumigant toxicity of a botanical-based feeding deterrent of the stable fly, Stomoxys calcitrans (Diptera: Muscidae). J Agric Food Chem 59:10394-10400 (2011).

28 Zhu JJ, Wienhold BJ, Wehrle J, Davis D, Chen H, Taylor DB et al., Efficacy and longevity of the newly developed microencapsulated-catnip as an oviposition deterrent and a larvicide against stable flies. Med Vet Entomol 28:222-227 (2014).
29 Zhu JJ, Cermak SC, Kenar JA, Brewer G, Haynes KF, Boxler D et al., Better than DEET repellent compounds derived from coconut oil. Sci Rep 8:14053 (2018).

30 Friesen K, Berkebile DR, Zhu JJ and Taylor DB, Laboratory rearing of stable flies and other muscoid Diptera. J Vis Exp 138:e57341 (2018).

31 Tangtrakulwanich K, Chen H, Baxendale F, Brewer G and Zhu JJ, Characterization of olfactory sensilla of Stomoxys calcitrans and electrophysiological responses to odorant compounds associated with their hosts and oviposition media. Med Vet Entomol 25:327-336 (2011).

32 Klun JA, Schmidt WF and Debboun M, Stereochemical effects in an insect repellent. J Med Entomol 38:809-812 (2001).

33 Zhu JJ, Dunlap C, Behle R, Berkebile D and Wienhold B, Repellency of a wax-based catnip-oil formulation against stable flies. J Agric Food Chem 58:12320-12326 (2010).

34 Tangtrakulwanich K, Albuquerque TA, Brewer GJ, Baxendale FP, Zurek L, Miller DN et al., Behavioral responses of stable flies to cattle manure slurry associated odorants. Med Vet Entomol 29:82-87 (2015).

35 Elzinga RJ and Broce AB, Labellar modifications of muscomorpha flies (Diptera). Ann Entomol Soc Am 79:150-209 (1986).

36 Thomas GD, Skoda SR, Berkebile DR and Campbell JB, Scheduled sanitation to reduce stable fly (Diptera, Muscidae) populations in beef cattle feedlots. J Econ Entomol 89:411-414 (1996).

37 Sukumar K, Perich MJ and Boobar LR, Botanical derivatives in mosquito control: a review. J Am Mosq Control Assoc 7:210-237 (1991).

38 Pitasawat B, Choochote W, Tuetun B, Tippawangkosol P, Kanjanapothi D, Jitpakdi A etal., Repellency of aromatic turmeric Curcuma aromatica under laboratory and field conditions. J Vector Ecol 28:234-240 (2003).

39 Thacker JRM, An Introduction to Arthropod Pest Control. Cambridge University Press, Cambridge (2002).

40 Isman MB, Botanical insecticides, deterrents, and repellents in modern agriculture and an increasingly regulated world. Annu Rev Entomol 51:45-66 (2006).

41 Mullens BA, Reifenrath WG and Butler SM, Laboratory trials of fatty acids as repellents or antifeedants against houseflies, horn flies and stable flies (Diptera: Muscidae). Pest Manag Sci 65:1360-1366 (2009).

42 Watson W, Lastro E, Rochon K, Denning S, Stringham M, Washburn S and Meier A, Insect Repellents in the Management of Horn Flies. North Carolina State University Extension, Raleigh (2011). http:// www.cefs.ncsu.edu/publications/dairyconferenceproceedings/ 18insectrepellentswatson.pdf

43 Baldacchino F, Tramut C, Salem A, Liénard E, Deletre E, Franc M et al., The repellency of lemongrass oil against stable flies, tested using video tracking. Parasite 20:21 (2013b).

44 Hieu TT, Jung JW and Kim Sl, Ahn YJ and kwon HW 2014. Behavioural and electroantennogram responses of the stable fly (Stomoxys calcitrans L.) to plant essential oils and their mixtures with attractants. Pest Manag Sci 70:163-172 (2014).

45 Zhu JJ, Berkebile DR, Dunlap CA, Zhang A, Boxler D, Tangtrakulwanich K et al., Nepetalactones from the essential oil of Nepeta cataria represent a stable fly feeding and ovipositional repellent. Med Vet Entomol 26:131-138 (2012)

46 Zhu JJ, Brewer GJ, Boxler DJ, Friesen K and Taylor DB, Comparisons of antifeedent activity and spatial repellency from three natural product repellents against horn flies (Diptera: Muscidae). Pest Manag Sci 71:1553-1560 (2015)

47 Han Y, Smits CHM, Brennan J, Page GI and Dam JJTPV, Animal feed additive and animal feed comprising alkyl esters of medium chain fatty acids, and their use in animal feed. US Patent 9861117B2 (2018). (https://patents.google.com/patent/US9861117B2/en14).

48 Cakir A, Essential oil and fatty acid composition of the fruits of Hippophae rhamnoides L. (sea buckthorn) and Myrtus communis L. from Turkey. Biochem Syst Ecol 32:809-816 (2004).

49 Moser BR, Eller FJ, Tisserat BH and Gravett A, Preparation of fatty acid methyl esters from Osage orange (Maclura pomifera) oil and evaluation as biodiesel. Energy Fuel 25:1869-1877 (2011).

50 Shao $\mathrm{H}$ and Tank $\mathrm{H}$, Tankmix additive conentrates containing trigryceride fatty acid esters and methods of use. US Patent 20130252812A1 (2013). (https://patents.google.com/patent/ US20130252812A1/en)

$51 \mathrm{Hu}$ Y-H and Somuah MO, Organic Pesticides from Hot Pepper Extracts. Kentucky State University Murray State's Digital Commons, Posters At-the-Capital (2018). https://digitalcommons.murraystate.edu/ postersatthecapitol/2007/KSU/2/. 
52 Kabara JJ, acids $\mathrm{F}$ and derivatives as antimicrobial agents, A review, in In the Pharmacological Effect of Lipids, Vol. I, ed. by Kabara JJ. American Oil Chemists Society, Champaign, pp. 1-14 (1978).

53 Huang CB, Alimova Y, Myers TM and Ebersole JL, Short- and medium-chain fatty acids exhibit antimicrobial activity for oral microorganisms. Arch Oral Biol 56:650-654 (2011).

54 Hogan JS, Pankey JW and Duthie AH, Growth inhibition of mastitis pathogen by long-chain fatty acids. J Dairy Sci 70:927-934 (1987).
55 Mubarak D, Praveenkumar R, Shenbagavalli T, Nivetha TM, Ahamed AP, Al-Dhabi NA etal., New reports on anti-bacterial and anti-candidal activities of fatty acid methyl esters (FAME) obtained from Scenedesmus bijugatus var. bicellularis biomass. RSC Adv 2:11552-11556 (2012).

56 Jackman J, Yoon BK, Li D and Cho N-J, Nanotechnology formulations for antibacterial free fatty acids and Monoglycerides. Molecules 21:305 (2016). 